\title{
An Assessment of Depo-Provera Injection Practice in Primary Health Care Facilities of Kilombero District, Tanzania
}

\author{
Article by A. Kalolella ${ }^{1}$, E. Mlay ${ }^{2}$, D. Danda ${ }^{3}$ \\ 1,2,3 Ifakara Health Institute, Dar es Salaam, Tanzania \\ E-mail: kalolella@hotmail.com
}

\begin{abstract}
The objective of this study was to assess Depo-Provera injection practice among health care workers (HCW) in primary health care facilities in kilombero district, Tanzania. The cross sectional descriptive design using structured observation checklist was used to collect data. About $261 \mathrm{HCWs}$ participated in the study to assess best practise of intramuscular injection technics and infection prevention measures. The SPSS descriptive statistics and chisquare tests were used to analyze data. Results indicate that majority of HCWs had adequately practiced infection prevention and intramuscular technics but did not perform well hand washing steps before and after giving injection. Many of them didn't check labels or shake vials before giving injection. Three quarter practiced critical steps of using sterile syringes, avoiding recapping the needle and use of safety box to discard contaminated sharps, while three quarter of HCW could not practice steps of hand wash before and after giving injection. Three quarter of participants correctly practiced filling drug into syringes, expel air from it, injected deep muscles, aspirated and pushed all drug into the muscles, Secondary graduates and nurse officer with diploma have significantly performed well in injection practice to ensure that before injecting the drug, aspirated through syringes and needle to ensure that the injecting needle is in the muscle and not in the vein. In conclusion, healthcare workers showed adequate practice of injection technics and infection prevention. However hand washing, drug label check and Depo-Provera preparation needs in house training and supervision.
\end{abstract}

Keywords: injection practice, contaminated waste, Blood borne infection, intramuscular injection technics, infection prevention.

\section{Introduction}

The injectable contraceptive such as Depo-Provera injection is among the most common family planning injection methods administered in health facilities worldwide for the purpose of prevention of pregnancy for the period of 3 months (WHO, 2011). The injectable contraceptive is most popular and preferred by Tanzanian women probably due to its simplicity in administering, privacy and confidentiality when using it (WHO, 2011). In this regards the use of injectable contraceptive-Depot-Provera is on increase especially in the rural areas where long term methods are not accessible. Usually the administration of injection is performed at heath facilities. Injection practice especially in low- and middle-income countries (LMICs) is blamed for multiple uses of unsafe injection procedures that lead to higher rate of transmission of blood-borne diseases (WHO, 2015). Individuals interacting in injection procedures and waste handling management: patients, health care worker $(\mathrm{HCW})$, community members may acquire blood borne infection as a results of contaminated waste (WHO, 2015). Unsafe injection practice and incorrect technique are common in many places in Sub-saharan Africa including Tanzania (Nilsson et al, 2013; WHO, 2015). Unsafe injection procedure is a risk factor for infection at injection sites, new incidences of HIV infection and fuel transmission of deadly blood borne virus such as: hepatitis B virus (HBV), hepatitis C virus (HCV) that may cause long term disability (WHO, 2010; Manchikanti, 2011).

According to Nilsson et al. (2013) unsafe injection contributed to 1.9 million (17\%) of new HIV infection in Sub-saharan Africa in 2010 alone. It is estimated that one third of two 
Texila International Journal of Public Health

Volume 5, Issue 1, Mar 2017

million individuals suffering from Hepatitis B acquired the disease through unsafe injection, while each year more than 3 million people acquires Hepatitis of which $40 \%$ was due to blood contaminated injection (Nilsson et al, 2013). Health care workers (HCW) in sub-Saharan Africa are more exposed to waste that are highly infectious including contaminated needles, sharps, and syringes that causing them annual estimated infection of 16,000 of $\mathrm{HCV}$ infections, 66,000 HBV and 1,000 HIV infections (Pruss-Ustun et al. 2005, WHO, 2010 ; Nilsson et al, 2013). Exposure to unsafe injection practice and incorrect technique may cause more harm which is costly to individuals and governments (Manchikanti, 2011; Nilsson et al, 2013).

A safe injection encompasses appropriate performance of introducing drug into the body without harming the patient, while not exposing any one to risk of infection or body damage due to injection and its waste products (Dolan et al, 2016; WHO, 2010; Nilsson et al, 2013). The injection safety practice is translated into a list of critical steps that must be followed in order to reduce risk to patient, service provider and surrounding community (Manchikanti, 2011; Nilsson et al, 2013). In these steps each injection should be administered with a new sterile syringe and needle, and provider should ensure right medication for patient (WHO, 2008; Hunter, 2007). The provider may avoid risk of exposure to infection by avoiding recapping the needle, and immediately discard used syringe and needle in a puncture-proof closed container (WHO, 2008; Hunter, 2007). The waste product after injection procedures should be safely managed to minimize risk hazard for the people, while all waste material should be disposed according to guidelines (WHO, 2008; Hunter, 2007; Hutin 2003). To ensure that any waste produced during performance of an injection procedure does not become a hazard for other people, used sharps waste and infectious non-sharps waste should be separated and safely managed and the final disposal of sharps containers and other medical waste should be conducted according to local and international health and environmental standards (WHO, 2008; Bartley, 2014).

The unsafe and risk practices include: reuse of injection equipment to administer to more than one client, use of multiple dose vials without changing used needles, reuse of syringes barrels or syringes barrels with needles, re use of injection equipment without sterilization and inadequate waste management (Hunter, 2013; Pepin et al, 2013). Incorrect practice exposes patients to harm and infectious diseases either directly, through contaminated needle and syringes or indirectly through medication vials that are contaminated with infectious blood or wrong medication and technical performance causing disability (WHO, 2015; Pepin et al, 2013).

Intramuscular injection is done in the denser part of the muscles: Mid-deltoid, Dorsogluteal, Rectus femoris, Vastus lateralis, and Ventrogluteal sites which are less painful due to fewer pain sensing nerve compared to other part of the body that is able to accommodate larger amount of solution. (Pepin et al, 2013; WHO, 2010). The Depo- Provera is conveniently administered in Mid-deltoid. The injection related infections and harm or complications are associated with wrong technical performance including: wrong site, incorrect depth of needle insertion, and wrong use of needle and syringes (Bartley, 2014, Hunter, 2008; WHO, 2010). Wrong intramuscular injection technical skills may result into intravascular injection, cellulitis, excessive pain, nerve damage, tissue fibrosis, and necrosis and abscess (Pepin et al, 2013; Bartley, 2014). Wrong or low dosage may result in medication error and efficacy problem (Bartley, 2014, Hunter, 2008). When giving injection HCW is required to choose an appropriate site where to insert the needle deep into muscles and then to withdraw the plunger slightly to ensure that the needle has not punctured or entered a blood vessel (Gyawali et al, 2013; Pepin et al, 2013). The plunger can then be pushed while injecting the medicinal solution slowly to give enough time for muscle tissue to expand to allow the required volume of solution to be accommodated (Pepin et al, 2013; Bartley, 2014). It is not advised to massage the area after injection, because the action may cause the drug content to be expelled from the injection site, introduce infection into injection wounds and may cause local tissue reaction and irritation (Hunter, 2008, WHO, 2015). Appropriate 
Infection prevention measures when combine with technical performance of injection procedures can reduce risks of harm and infection to patient, $\mathrm{HCW}$ and the community where injection exercise is conducted due to poor waste management (Nilsson et al., 2013; Hutin et al., 2003).

In this study we assessed Depo-Provera (injectable contraceptive) intramuscular injection practice among health care workers in public primary health care facilities of Kilombero district, Tanzania.

\section{Procedures and methods}

\section{Study design}

The cross section design was used in combination with structured observation checklists of important steps in giving Depo- Provera injection. The study was conducted in April- June, 2016 at 29 public primary health facilities that provide Depo-Provera in Kilombero district, southern part of Tanzania. The HCWs that practiced Depo-Provera were enrolled in this study. There were $261 \mathrm{HCWs}$ that participated in giving injection of Depo-Provera; Primary and secondary school graduates, trained nurse, enrolled nurse and nurse officers. Data collection was done using direct observation questionnaires developed using WHO and Tanzanian Ministry of health guideline for infection prevention and injection technical performance procedures (Tanzania, 2004; Hutin, 2003; WHO, 2015). The questionnaire employed close-ended responses of " 1 " when $\mathrm{HCW}$ performed the required step or number "o" when the step was not performed.

Infection prevention and intramuscular injection technical steps were observed. The following steps were observed for infection prevention; washing hands using clean water and soap or alcohol hand rub, use of clean towel to dry hand or drying them on open air, using of sterile syringe and needle, avoiding recapping needle to prevent NSI, avoiding antiseptic to clean injection site, to wash hand after injection procedures, to avoid messaging injection site, informing client not massage injection site to avoid introducing infection and discarding all contaminated injection equipment and material into the safety-box (WHO, 2015, Hunter, 2007; Bartley. 2014). During the administration of Depo-Provera, HCW were observed if they have conducted all necessary technical steps for intramuscular injection; checking the vial for appropriateness and expiry dates, gently shaking of the vial to homogenize the solution, filling the syringe with all drug from the vial, pushing solution to expel air from the syringe, properly inserting the needle deep the muscle, (6) aspirates to ensure needle is not in a vein, inject the entire contents of the syringe. (WHO, 2015, Hunter, 2007).

\section{Ethical permission}

The ethical permission for the study was sought from the Medical Research Coordinating Committee of National Institute for Medical Research (NIMR), while Ifakara health Institute provided research clearance. An informed consent was sought from nurse to be observed and women receiving injection.

\section{Data analysis}

The data entry and analysis was conducted using the Statistical Package for Social Sciences (SPSS) version 19.0. Different variables were categorized and entered and as follows; gender, academic qualification, professional qualification, work experience, steps observed for infection prevention during injection practice, and steps observed for intramuscular injection technical performance. All steps were categorized as "performed "or "not performed" critical safety step of Depo-Provera injection practice (WHO, 2010). Frequency tables and cross tabulations were used to inform any associations between these variables and was also used to determine if academic and professional achievements and work experience among HCW were associated with practice of safe injections practice. The chisquire test was used to analyze categorical data to test statistical significance between these 
Texila International Journal of Public Health

Volume 5, Issue 1, Mar 2017

differences or association between proportions of steps observed during direct observation process, while the association or the differences were considered significant if $\mathrm{P}$-values $<0.05$.

\section{Results}

Two hundred and sixty one $(\mathrm{n}=261)$ healthcare workers were involved in the research. Among them $8(3 \%)$ were males and $253(97 \%)$ were female. With respect to academic qualification, $76(29.2 \%)$ completed primary education while $179(65.3 \%)$ attended ordinary level secondary education. These who received professional training were as follows; 67 $(25.7 \%)$ were trained nurse, $160(61.3 \%)$ enrolled nurse, $18(6.9 \%)$ were diploma holder nurses. About one-third had experience of 1-4 years and two third had experience of 5 years and above (Table I).

Table I. Demographic characteristics $(n=261)$

\begin{tabular}{|l|l|l|l|}
\hline Variable & Response & Frequency & Percent \\
\hline Gender in sex & Male & 8 & 3.07 \\
\cline { 2 - 4 } & Female & 253 & 96.93 \\
\hline Academic & Primary education & 76 & 29.23 \\
\cline { 2 - 4 } & Secondary education & 179 & 65.38 \\
\cline { 2 - 4 } & Missing Data & 6 & 2.30 \\
\hline \multirow{3}{*}{$\begin{array}{l}\text { Profession } \\
\text { Qualification }\end{array}$} & Trained- No certificate & 67 & 25.7 \\
\cline { 2 - 4 } & Enrolled nurse-certificate & 160 & 61.30 \\
\cline { 2 - 4 } & Nurse officer- Diploma & 18 & 6.90 \\
\cline { 2 - 4 } & Missing Data & 16 & 6.13 \\
\hline \multirow{4}{*}{$\begin{array}{l}\text { Working } \\
\text { experience }\end{array}$} & $1-4$ years & 86 & 32.95 \\
\cline { 2 - 4 } & 5 years and above & 167 & 63.98 \\
\cline { 2 - 4 } & Missing Data & 8 & 3.07 \\
\hline
\end{tabular}

In infection prevention, about three quarter of $\mathrm{HCW}$ could not perform critical steps of hand wash and drying before and after giving injection (Table II). However more than three quarter were able to perform critical steps of using sterile syringes, avoiding recapping the needle and use of safety box to discard contaminated sharps (Table II). In injection giving technics more than three quarter of participants were able to correctly fill drug into syringes, expel air from it injected deep muscles, aspirated to ensure that needle is not in vein and pushed all drug into the muscles, while about three quarter were not able to check the vials for appropriateness and expiry date and could not shake the vial to mix up drug contents (Table II).

Table II. The practice of critical steps in intramuscular injection technics and Infection prevention $(\mathrm{n}=$ 261)

\begin{tabular}{|l|l|l|l|}
\hline Variable & Performed & Not performed & Missing Data \\
\hline $\begin{array}{l}\text { Injection Infection } \\
\text { Prevention Practice }\end{array}$ & $\mathrm{n} \mathrm{( \% )}$ & $\mathrm{n}(\%)$ & $\mathrm{n} \mathrm{( \% )}$ \\
\hline $\begin{array}{l}\text { Before Injection hand } \\
\text { cleaning }\end{array}$ & $64(24.52)$ & $195(74.71)$ & $2(0.77 \%)$ \\
\hline Hand drying & $65(24.90)$ & $195(74.33)$ & $2(0.77 \%)$ \\
\hline $\begin{array}{l}\text { Using sterile syringe } \\
\text { and needle }\end{array}$ & $246(95.25)$ & $15(5.75)$ & \\
\hline $\begin{array}{l}\text { No recapping of } \\
\text { needle }\end{array}$ & $220(84.29)$ & $41(15.71)$ & \\
\hline Cleaning injection site & $176(67.43)$ & $85(32.57)$ & \\
\hline $\begin{array}{l}\text { Safety box Injection } \\
\text { discard }\end{array}$ & $194(74.33)$ & $66(25.29)$ & $1(0.38 \%)$ \\
\hline
\end{tabular}


Texila International Journal of Public Health

Volume 5, Issue 1, Mar 2017

\begin{tabular}{|l|l|l|l|}
\hline $\begin{array}{l}\text { After injection hand } \\
\text { cleaning }\end{array}$ & $69(26.44)$ & $189(72.41)$ & $3(1.15 \%)$ \\
\hline $\begin{array}{l}\text { No message of } \\
\text { injection site }\end{array}$ & $114(43.68)$ & $147(56.32)$ & \\
\hline $\begin{array}{l}\text { Injection Technical } \\
\text { performance Practice } \\
\text { (ITP) }\end{array}$ & & & \\
\hline Vial check & $65(24.90)$ & $189(72.41)$ & $7(2.68 \%)$ \\
\hline Vial gently shaking & $63(24.14)$ & $198(75.86)$ & \\
\hline $\begin{array}{l}\text { Correctly filling of } \\
\text { syringe }\end{array}$ & $248(95.02)$ & $13(4.98)$ & \\
\hline Expels air & $199(76.25)$ & $62(23.75)$ & \\
\hline $\begin{array}{l}\text { Inserts needle deep the } \\
\text { muscle }\end{array}$ & $231(88.51)$ & $30(11.49)$ & \\
\hline $\begin{array}{l}\text { Aspirate through } \\
\text { needle }\end{array}$ & $220(84.29)$ & $41(15.71)$ & \\
\hline $\begin{array}{l}\text { inject the entire } \\
\text { contents }\end{array}$ & $227(86.97)$ & $34(13.03)$ & \\
\hline
\end{tabular}

Nurses with secondary education reported significant more performance of critical safety steps of cleaning hands after providing injection and avoiding messaging the injection site to prevent introducing infection to injection wound (Table III). Performance of other infection prevention steps were not significantly different among primary and secondary graduates. In in injection technics, secondary graduates showed significant more performance in checking vials for appropriateness and expiry dates and aspiration of injected needle to make sure that the needle is not in vein to avoid injecting drugs into blood vessels that may cause drug complications (Table III).

Table III. Practice of critical safety steps in Infection prevention and intramuscular injection technics based on academic qualification

\begin{tabular}{|l|l|l|l|}
\hline Variable & $\begin{array}{l}\text { Primary } \\
\text { education } \\
(\mathrm{n}=76)\end{array}$ & $\begin{array}{l}\text { Secondary } \\
\text { education } \\
(\mathrm{n}=179)\end{array}$ & P-Value \\
\hline Injection Infection Prevention Practice & $\mathrm{n}(\%)$ & $\mathrm{n}(\%)$ & \\
\hline Before Injection hand cleaning & $15(19.74)$ & $46(25.70)$ & NS \\
\hline Hand drying & $16(26.26)$ & $47(21.05)$ & NS \\
\hline Using sterile syringe and needle & $73(96.05)$ & $168(93.85)$ & NS \\
\hline No recapping of needle & $63(82.89)$ & $153(85.47)$ & NS \\
\hline Cleaning injection site & $50(68.16)$ & $122(65.79)$ & NS \\
\hline Safety box Injection discard & $52(68.42)$ & $138(77.09)$ & NS \\
\hline After injection hand cleaning & $17(22.37)$ & $51(28.49)$ & 0.020 \\
\hline No message of injection site & $23(30.26)$ & $90(50.28)$ & 0.003 \\
\hline $\begin{array}{l}\text { Injection Technical Performance } \\
\text { Practice }\end{array}$ & & & \\
\hline Vial check & $14(18.42)$ & $51(28.49)$ & $<0.001$ \\
\hline Vial gently shaking & $53(69.74)$ & $142(79.33)$ & NS \\
\hline Correctly filling of syringe & $72(94.74)$ & $171(95.53)$ & NS \\
\hline Expels air & $59(77.63)$ & $135(75.42)$ & NS \\
\hline Inserts needle deep the muscle & $63(82.89)$ & $163(91.06)$ & NS \\
\hline Aspirate through needle & $58(76.32)$ & $157(87.71)$ & 0.022 \\
\hline inject the entire contents & $68(89.47)$ & $156(87.15)$ & NS \\
\hline
\end{tabular}


Texila International Journal of Public Health

Volume 5, Issue 1, Mar 2017

In infection prevention, nurses with diploma showed significant more performance of hand cleaning and drying before and after giving injection and in avoiding messaging the injection site to prevent introduction of infection in injection site (Table IV). The trained nurses showed significant more performance in avoiding the recapping the needle to prevent NSI, while enrolled nurse showed significant more performance in using of safety box to discard sharps. In injection technics, nurse officers with diploma have significantly performed well in ensuring that before injecting the drug, they were able to aspirate through syringes and needle to ensure that the injecting needle is in the muscle and not in the vein or artery for safe medication of Depo-Provera (Table IV)

Table IV. Practice of critical safety steps of Infection prevention and intramuscular technics based on professional qualification

\begin{tabular}{|l|l|l|l|l|}
\hline Variable & $\begin{array}{l}\text { Trained } \\
\mathrm{N}=67\end{array}$ & $\begin{array}{l}\text { Certificate } \\
\mathrm{N}=160\end{array}$ & $\begin{array}{l}\text { Diploma } \\
\mathrm{N}=18\end{array}$ & P- Value \\
\hline Infection Prevention practice & $\mathrm{N}(\%)$ & $\mathrm{N}(\%)$ & $\mathrm{N}(\%)$ & \\
\hline Before Injection hand cleaning & $2(31.25)$ & $47(29.38)$ & $10(55.56)$ & $<0.001$ \\
\hline Hand drying & $0(0.000)$ & $49(30.63)$ & $9(50.00)$ & $<0.001$ \\
\hline Using sterile syringe and needle & $64(95.52)$ & $151(94.38)$ & $16(88.89)$ & $\mathrm{NS}$ \\
\hline No recapping of needle & $61(91.04)$ & $134(83.75)$ & $15(83.33)$ & 0.044 \\
\hline Cleaning injection site & $45(67.16)$ & $102(63.75)$ & $14(77.78)$ & $\mathrm{NS}$ \\
\hline Safety box Injection discard & $51(76.12)$ & $124(77.50)$ & $13(72.22)$ & 0.037 \\
\hline After injection hand cleaning & $5(7.46)$ & $48(30.00)$ & $11(61.11)$ & $<0.001$ \\
\hline No message of injection site & $16(23.88)$ & $78(48.75)$ & $9(50.00)$ & 0.001 \\
\hline $\begin{array}{l}\text { Injection Technical Performance } \\
\text { Practice }\end{array}$ & & & & \\
\hline Vial check & $11(16.42)$ & $45(28.19)$ & $6(33.33)$ & $\mathrm{NS}$ \\
\hline Vial gently shaking & $51(76.12)$ & $120(75.00)$ & $14(77.78)$ & $\mathrm{NS}$ \\
\hline Correctly filling of syringe & $66(98.51)$ & $150(93.75)$ & $16(88.89)$ & $\mathrm{NS}$ \\
\hline Expels air & $54(80.60)$ & $115(71.88)$ & $16(88.89)$ & $\mathrm{NS}$ \\
\hline Inserts needle deep the muscle & $60(89.55)$ & $142(88.75)$ & $17(94.44)$ & $\mathrm{NS}$ \\
\hline Aspirate through needle & $64(95.52)$ & $128(80.00)$ & $16(85.89)$ & 0.019 \\
\hline inject the entire contents & $59(88.06)$ & $139(86.88)$ & $17(94.44)$ & $\mathrm{NS}$ \\
\hline
\end{tabular}

The work experience has little to do with practices of infection prevention and injection technical performance. There were no significant differences in the performances between different study groups (Table V).

Table V. Practice of critical safety steps for infection prevention and technical performance according to working experience

\begin{tabular}{|l|l|l|l|}
\hline Variable & $\begin{array}{l}<5 \text { years } \\
\mathrm{N}=86\end{array}$ & $\begin{array}{l}>5 \text { years and } \\
\text { above N=167s }\end{array}$ & P- Value \\
\hline $\begin{array}{l}\text { Injection Infection Prevention } \\
\text { Practice }\end{array}$ & $20(23.26)$ & $40(23.95)$ & NS \\
\hline Before Injection hand cleaning & $24(27.91)$ & $37(22.16)$ & NS \\
\hline Hand drying & $81(94.19)$ & $157(94.01)$ & NS \\
\hline Using sterile syringe and needle & $76(88.37)$ & $137(82.04)$ & NS \\
\hline No recapping of needle & $55(63.95)$ & $114(68.26)$ & NS \\
\hline Cleaning injection site & $66(76.74)$ & $122(73.05)$ & NS \\
\hline Safety box Injection discard & $15(17.44)$ & $50(29.94)$ & NS \\
\hline After injection hand cleaning & $38(44.19)$ & $70(41.92)$ & NS \\
\hline No message of injection site & & & \\
\hline $\begin{array}{l}\text { Injection Technical Performance } \\
\text { practice }\end{array}$ & & & \\
\hline
\end{tabular}




\begin{tabular}{|l|l|l|l|}
\hline Vial check & $22(25.58)$ & $40(23.95)$ & NS \\
\hline Vial gently shaking & $70(81.40)$ & $73.65(73.65)$ & NS \\
\hline Correctly filling of syringe & $83(96.51)$ & $157(94.01)$ & NS \\
\hline Expels air & $70(81.40)$ & $123(73.65)$ & NS \\
\hline Inserts needle deep the muscle & $79(91.86)$ & $145(86.83)$ & NS \\
\hline Aspirate through needle & $68(79.07)$ & $145(86.83)$ & NS \\
\hline inject the entire contents & $79(91.86)$ & $140(83.83)$ & NS \\
\hline
\end{tabular}

For hand cleaning for injection, only $24 \%$ of participants were able to clean their hand before handling injection equipment and material and only $26 \%$ were able to wash they hand after administering injection which is risk practice for spreading of infectious diseases between client and health service provider as well as spreading infection to others through contaminated hands and surfaces touched (Table II). In injection technical performance, very few staffs $(25 \%)$ were able to carefully check vial label for appropriateness and for expiry date which is very important for contraceptive function. Expired contraceptive cannot work as expected and cannot prevent pregnancy resulting into unintended pregnancy. Only $24 \%$ participants shacked the vial to homogenize the mixture for proper functions of the contraceptive medicine (Table II).

Both groups of nurses with primary and secondary academic qualifications could not perform well for hand cleaning before injection by $19 \%$ and $25 \%$ respectively, while only $17 \%$ participants with primary academic qualification washed their hand after injection procedures and only $30 \%$ of them followed the guideline of avoiding messaging the injection site risk factor of infection to injection wound (Table III).

Trained nurse and enrolled nurse had poor performance of infection prevention steps of cleaning hand before injection at $31 \%$ and $29 \%$ respectively, while washing hand after performance of injection procedure were $7 \%$ and $30 \%$ respectively, and few of them follow the guideline of avoiding messaging the injection site to avoid introducing infection by $23 \%$ and $48 \%$ respectively (Table IV).

The performance of hand washing was a big problem for both group of work experience (these with less than 5 years and those more than five years). Before injection procedure hand washing was $23 \%$ for participant with experience of less than five years and $23 \%$ for others (Table IV), while hand washing after injection administration was $17 \%$ and $29 \%$ respectively. In checking the vials for expiry date and labels only $25 \%$ participants with experience less than five years and $23 \%$ for other did follow the step (Table V).

\section{Discussion}

This study was conducted in public facilities providing injectable contraceptive in kilombero district eastern Tanzania, may be considered as an example of many primary health care facilities in the rural areas in low income country with a high burden of blood transmissible diseases such as HIV cases. The Sub Saharan Africa, experience the highest levels of HIV/AIDS, while millions of women of reproductive age expected to receive injectable contraceptive are currently living with HIV in sub-Saharan Africa (Calvert \& Ronsmans, 2015). In Tanzania, almost $7 \%$ of pregnant women who are expecting to start any form of contraceptive including injectable after delivery were diagnosed with HIV in antenatal clinics in 2015 (PMTCT Tanzania, 2016). The injection practices; infection prevention and injection technical steps for safety are important to preventing new HIV and other blood borne infection to reduce mortality.

The healthcare workers in this research showed acceptable professional behaviors of following guidelines of important safety steps when injecting contraceptive drug. However observed lower performance of washing hands before and after giving injection. Performance of washing hand is expressed as a important safety step toward infection prevention as established in guideline (WHO, 2010, Tanzania, 2004). Washing hand prevent contamination 
Texila International Journal of Public Health

Volume 5, Issue 1, Mar 2017

of injection equipment and materials and reduce transmission of infection from one individual to another.

The study indicated that many health care worker were not able to care full check the vial label for appropriateness and for expiry date which is very important for contraceptive. Expired contraceptive cannot work as expected and cannot prevent pregnant resulting into unintended pregnancy which is very common in Tanzania. The label checking is important to avoid harming patients by injection them other drug that are not prescribed by their doctors. This problem may not be for injectable contraceptive only, but may also be practiced for other drugs, medications and contraceptives which is dangerous for health of clients.

The study shows that large majority of participants did not shake the vial to homogenize the mixture of the contraceptive medicine. The Depo-provera should be vigorously shaken just before use to ensure that the dose being administered represents a uniform suspension as indicated in the manufacturer guideline (Pharmacia and Upjohn Company, 2009). The Depoprovera contraceptive injection contains; medroxyprogesterone acetate, a derivative of progesterone, as its active ingredient of medroxyprogesterone acetate sterile aqueous suspension $150 \mathrm{mg} / \mathrm{mL}$. Each $\mathrm{mL}$ contains: Medroxyprogesterone acetate $150 \quad \mathrm{mg}$, Polyethylene glycol 3350-28.9 mg, Polysorbate 80- $2.41 \mathrm{mg}$, Sodium chloride $8.68 \mathrm{mg}$, Methylparaben $1.37 \mathrm{mg}$, Propylparaben $0.150 \mathrm{mg}$, and water for injection (Pharmacia and Upjohn Company, 2009). All components are important and can functions well only when homogenized. For example, sodium chloride has a function of maintenance of PH important factor in drug efficacy (Pharmacia and Upjohn Company, 2009). Unshaken vials may be contributing to poor efficacy, unintended pregnancy and drug side effects.

The observation highlighted the gap in the basic practices of infection prevention and intramuscular technical performance, particular in Depo-Provera preparations. The research finding showed that there is need of further training and education about washing hand to avoid transmitting infection including HIV and other blood borne infections. The Training is also needed on how to prepare Depo-Provera before it is administered in the muscles with emphasis of manufacturer guidelines, such as vigorously shaking the vial to homogenize the solution for effective functions.

\section{Conclusion}

In this research we can conclude that health workers in primary health care facilities of Tanzania, to a large extent observed to adequately practice Depo-provera intramuscular injection and infection preventive measures to avoid health complications and prevent acquiring serious infections. They have practiced according to the guideline while working with Depo-provera drug, injection equipment and materials. However more improvements can be made to ensure satisfactory hand washing to avoid and prevent transmission of infections. Health care workers should also improve their ways of preparation of DepoProvera prior to its administration.

\section{Acknowledgements}

We would like to thank and express our gratitude to the District reproductive health coordinator in Kilombero district, in charges of health facilities and health workers of reproductive and child health section of the primary health care facilities and all participants for their support of time and willingness to accept this study. The study was funded by the United States International development. 


\section{References}

[1]. Bartley N, 2014. Guidelines on the Administration of Intramuscular and Sub-Cutaneous Injections, Retrieved January 16, 2016 from http:/www.olchc.ie/Healthcare-Professionals/Nursing-PracticeGuidelines/Intramuscular-and-Sub-Cutaneous-Injections-Administration.pdf.

[2]. Calvert C, Ronsmans C. (2015). Pregnancy and HIV disease progression: a systematic review and meta-analysis. Journal of Tropical Medicine and International Health, 20(2):122-45. Retrieved June 5, 2016, from PubMed.

[3]. Gyawali S ${ }^{1}$, Rathore DS, Shankar PR, Kumar KV. (2013). Strategies and challenges for safe injection practice in developing countries. J Pharmacol Pharmacother. 2013 Jan; 4(1):8-12. doi: 10.4103/0976-500X.107634.

[4]. Hutin Y, Anja Hauri, Linda Chiarello, Mary Catlin, Barbara Stilwell, Tesfamicael Ghebrehiwet, Julia Garner \& the Members of the Injection Safety Best Practices Development Group (2003). Best infection control practices for intradermal, subcutaneous, and intramuscular needle injections, Bulletin of the World Health Organization 2003;81:491-500. Retrieved January 20, 2016 from http://www.who.int/bulletin/volumes/81/7/Hutin0703.pdf.

[5]. Hunter J. Intramuscular injection techniques. Nurs Stand. 2008 Feb 20-26;22(24):35-40.

[6]. Nilsson J, Andrea B. Pembe, Miriam Urasa, and Elisabeth Darj (2013). Safe injections and waste management among healthcare workers at a regional hospital in northern Tanzania. Tanzania Journal of Health Research Doi: http://dx.doi.org/10.4314/thrb.v15i1.8 Volume 15, Number 1, January 2013.

[7]. Pharmacia and Upjohn Company DEPO-PROVERA ${ }^{\circledR}, 2009$. Medroxyprogesterone acetate injection, suspension: Physician Information. Retrieved from https://dailymed.nlm.nih.gov/dailymed/archives/fdaDrugInfo.cfm?archiveid=1156.

[8]. Laxmaiah Manchikanti, MD, Yogesh Malla, MD, Bradley W. Wargo, DO, and Bert Fellows, M, 2011. Infection Control Practices (Safe Injection and Medication Vial Utilization) for Interventional Techniques: Are They Based on Relative Risk Management or Evidence? Pain Physician 2011; 14:425-434 • ISSN 1533-315.

[9]. Pepin J, Abou Chakra CN, Pe'pin E, Nault V, 2013. Evolution of the Global Use of Unsafe Medical Injections, 2000-2010. PLoS ONE 8(12): e80948.doi:10.1371/journal.pone.0080948.

[10]. Prüss-Üstün A, Rapiti E, Hutin Y. Estimation of the global burden of disease attributable to contaminated sharps injuries among health-care workers. American Journal of Industrial Medicine, 2005, 48(6):482-490. Retrieved from

http://www.who.int/quantifying_ehimpacts/global/7sharps.pdf.

[11]. PMTCT Tanzania. National resource centre for prevention of mother to child HIV transmission (2016). Retrieved June 15, 2016 from http://pmtct.or.tz/pmtct-tanzania/pmtct-in-tanzania/.

[12]. Susan A. Dolan, Kathleen Meehan Arias, Gwen Felizardo, Sue Barnes, Susan Kraska, Marcia Patrick, Amelia Bumsted (2016). APIC POSITION PAPER: SAFE INJECTION, INFUSION, AND MEDICATION VIAL PRACTICES IN HEALTH CARE. Retrieved 20 March, 2016 from http://www.apic.org/Resource_/TinyMceFileManager/Position_Statements/2016APICSIPPositionPape r.pdf.

[13]. Tanzania (2004) National Infection Prevention and Control Guidelines for Health Care Services in

[14]. Tanzania. Ministry of Health and Social welfare, The United Republic of Tanzania, Dar es Salaam.

[15]. World Health Organization, 2010. WHO Best Practices for Injections and Related Procedures Toolkit Geneva: 2010 Mar. ISBN-13: 978-92-4-159925-2. Retrieved from http://www.ncbi.nlm.nih.gov/books/NBK138491/PubMed.

[16]. World Health Organization. (2008). Revised injection safety assessment tool. Retrieved from http://www.who.int/injection_safety/Injection_safety_final-web.pdf

[17]. World Health Organization, 2015. WHO Guideline on the Use of Safety-Engineered Syringes for Intramuscular, Intradermal and Subcutaneous Injections in Health-Care Settings. Geneva: Retrieved from http://www.ncbi.nlm.nih.gov/books/NBK305368/.

[18]. World Health Organization, 2011. Family planning: a global handbook for providers. WHO regional publication. 